\title{
Building bridges between research on politics and political action
}

\section{Eva Lichtenberger}

former Member of the European Parlament

eva.lichtenberger@chello.at
It should be obvious that the results of research by political scientists can be relevant for politicians. In everyday political life, however, there are numerous obstacles to an intensive and fruitful exchange between research and politics. For starters, academic publications are not always easy to find for potential readers. Moreover, there is often a lack of time and opportunity for intensive debates on relevant topics. Apart from a few exceptions, political scientists and politicians appear to live in different "bubbles". Building bridges between these bubbles would be a very positive undertaking for both sides. Personal contacts, joint projects and an active creation of meeting spaces could help in closing the gap between academia and politics.

\section{The relevance of political science for my political career}

I already gained detailed knowledge about the political system of Austria during my studies at the Department of Political Science in Innsbruck - not only in the lectures and seminars, but also through my work as a student respresentative in commissions and through our efforts to enlarge the capacities of the department and to establish a chair for gender studies in Innsbruck. In particular, the second project of a new chair for gender studies seemed quite hopeless at the beginning and the search for strategies against the resistance of the conservative forces at the university required a good grasp of its political and institutional framework. At the same time, I was already active as a spokesperson of a citizens' initiative. Here, too, the basic knowledge I had acquired at university was very helpful. Through contacts with the spokespersons of other initiatives I was able to see how difficult it was for them to classify political decisions or commitments and to navigate between legal and political frameworks.
This knowledge also proved to be valuable in my later career in Tyrolean and in European politics. I still remember one event very well: When a reform of the electoral law was discussed in Tyrol in the I990s, one topic was, of course, the assessment of the consequences of individual paragraphs of the new law for the parties in the Tyrolean parliament. Discussions with lecturers and students of political science were very helpful for the decision.

When the National Parliament sent me to the Convention for a European Constitution as one of Austria's substitute delegates, the competences acquired at university, my contacts to scholars of political science and my knowledge of the political-science literature became particularly important to me. At the Convention, we had to deal with a huge number of amendments and proposals from other members. All of these documents had to be analyzed, which could hardly be done alone. In this context, the dialogue with constitutional experts proved to be very helpful for Mr. Caspar Einem and myself. Beyond that, political considerations were also necessary, as well as the consideration of fundamental ideas of a constitution and the analysis of political motives of different groups of delegates.

Likewise, I repeatedly drew on studies of political scientists in my later work in the European Parliament. In my communication with other MEPs, who did not have close contact to scientific material, I was able to observe that well-founded knowledge has positive effects: it protects against false attributions of blame to individual decision-makers and - by providing insights into political processes - against against too much impatience regarding the speed of political decisions. Finally, this knowledge is also very helpful for analysing the political environment of a decision. For my contacts with countries outside of Europe, analyses from academia were indispensable for preparing projects of cooperation on specific topics as well as meetings with delega- 
tions of non-European states. A prime example of this was the "Directive on the disclosure of non-financial and diversity information by certain large companies and groups ${ }^{{ }^{\prime}}$ which we discussed with parlamentarians from the United States and decided in close contact with them since both parliaments dealt with this topic at the very same time. This cooperation finally made it possible to cover a very large portion of companies with global activities and to achieve, by means of well comparable regulations, that negative practices were at least made public and thus made easier to correct by public pressure. This, of course, required a basic knowledge of the decision-making mechanisms and their backgrounds in the United States.

\section{Political consulting versus political science}

Beyond my personal experiences, I have the impression that there is still room for deepening contacts between political science and politics. Political-science research would offer a rich reservoir for the concrete shaping of political action, but there is relatively little request for it and a lack of contact. As a consequence, research has only a limited impact on political decisions. The most likely way to engage in debates is through personal contacts - at regional and national level as well as in the "Brussels bubble". Yet political scientist use this way of engagement neither intensively nor systematically. It is very rare for them to approach members of parliament directly and present their research to them. In individual cases, however, there are fruitful cooperations, such as those between a Tyrolean member of the European Parliament and the Department of Political Science at the University of Innsbruck on the subject of international trade agreements and the their parliamentary control ${ }^{2}$. This expert opinion has significantly influenced the voting behaviour of the (Austrian) Social Democrats in the European Parliament.

There are also occasional contacts through the Brussels think tanks, which repeatedly invite active politicians to debates and working groups in which results of political-science research are presented. An example of this was the initiative of the Centre for European Policy Studies (CEPS) for a high-level group on the topic of a reform of the European institutions without prior amendment of the Lisbon Treaty - with the participation of some active and former members of the European Parliament, members of the Council and the Commission

I http://eur-lex.europa.eu/legal-content/DE/TXT/PDF/?uri=CELEX:3 20I4Loo95\& from $=$ EN

2 Expert opinion A. Maurer on the additional declarations in the trade agreement between the European Union and Canada for the Socialist Group in the European Parliament. as well as representatives of academia ${ }^{3}$. This report had a direct political impact as parts of the proposals were implemented by the Juncker Commission. Examples like these could serve as motivation for political scientists to look out for such types of cooperation more often.

According to my experience, the above-mentioned examples are more of an exception than a rule. So the question remains as to why the knowledge pool of political science is not used more frequently in political decision making. In the run-up to the seminar "Cui bono scientia Politica? A Debate on the Relevance of (Austrian) Political Science", which took place in October 2017 in Innsbruck, I discussed with some of my former colleagues whether they would resort to political-science research in their political work. The answers they gave only have anecdotal value, but they are in line with my own experience. A number of colleagues stated that the work of political scientists would certainly be very enriching, but that they simply lacked the time for an indepth examination of their publications. In this context it also necessary to know that the recent past has been characterized by a strong acceleration and densification in political work. As far as the European Parliament is concerned, this also meant an increase in meetings and appointments. In particular, the trend towards first reading agreements often requires several trilogue ${ }^{4}$ meetings to be scheduled in addition to the normal committee work and requires meticulous preparation of the content and additional expert meetings. In addition, the more frequent use of new media in politics has shortened the reaction times and requires decision-makers to issue statements before they had enough time to obtain background information on a topic.

But this is certainly not the only factor. It is not easy for politicians without an academic background to find political-science publications relevant to their field of work. Probably a portal with good search functions would be suitable to make articles and books more accessible to a wider readership. Such a portal should be located at the European level, but also at the national and regional parliaments, as close as possible to the political bodies. In the case of the European Parliament it might be a good idea to cooperate with the scientific service of the European Parliament (EPRS) ${ }^{5}$, which prepares briefings for members of parliament on specific topics with references to literature.

3 Report of the CEPS High-Level Group, Chair Danuta Hübner, Shifting EU Institutional Reform into High Gear, CEPS, Brussels 2014.

4 Trilogue meetings take place after the conclusion of the deliberations of the parliamentary committees and the respective Councils of Ministers, which, including the Commission, try to reach an agreement in confidential meetings on contentious issues in order to avoid a second reading.

5 The European Parliamentary Research Service is a section of the EP and offers publications and fact-sheets to the Members of European Parliament. 
Another possibility would, of course, be to contact political groups or individual members of parliament who deal with specific topics. This, however, requires meaningful fact-sheets or abstracts that make a concrete reference to the field of work of the respective decisionmakers. Specific policy briefs are a user-friendly way of reaching people without a scientific education, if they are worded accordingly. The time pressure mentioned above makes it difficult to bring long and complex texts to the knowledge of active politicians. A large part of the preparatory work in terms of content is done by the staff in the offices of the members of parliament or in the parliamentary groups, who are also interesting contacts for networking.

In any case, writing abstracts or policy briefs is a special challenge for teaching and practice. Students of political science should therefore not only learn to write scientific texts but also to "market" them in a version that is intelligible for people without an academic background.

Easy access to political decision-makers can certainly be found - directly or indirectly - through events or discussions. In the European Parliament, for example, political groups have very good conditions for the organisation of seminars or events on specific topics. The Group of the Greens/European Free Alliance as well as other political groups have often invited representatives of political science from EU member states on such occasions. Recently, these events have also often been made accessible via streaming on the Internet, which has often resulted in considerable rates of (online) participation.

Aside from that, it is usually events, seminars and public discussions in which politicians and their staff get in touch with political scientists. More than political parties themselves, political foundations invite speakers who offer a thorough analysis of political processes or backgrounds for a mostly party-oriented audience. Other organisers like NGOs are also active in this field. Of course, many political scientists can be found in this context. There are good contacts, but they could be used and stimulated to a greater extent. This could take place in the form of permanent cooperation or selectively.

A current example of self-organised political events beyond party structures is "Pulse of Europe". In these spontaneous gatherings of citizens, the electoral successes of the Eurosceptic parties and the Brexit were reacted to and an attempt was made to articulate a positive attitude towards the European Union as a counterweight to the prevailing Euroskepticism. This movement was mostly carried by young people and was strongly concentrated in the capitals of the member states of the Union. To acquire competence and to generate public attention, these decentralised groups also invited researchers. Meanwhile, this movement has become less visible. So perhaps it is an example of a new type of citizens' movements that acts and reacts very spontaneously but does not develop permanent organisational patterns.

Basically, there is a great need for strategic advice in politics - and depending on the financial strength of the parties and organisations, there are studies commissioned at universities. According to my personal perception, the need for consulting services or studies has increased recently. This could be due to the fact that the political systems are in a state of rapid change and the complexity of these developments seems to be very demanding for individual decision-makers. On the one hand, this gives rise to a desire for expertise that should be as practical as possible. On the other hand, wellknown experts are often sought to advise on internal organisational and strategic decisions. Unfortunately, such contacts concentrate on election campaigns in particular, and thus the overall view often vanishes in favour of short-term and particular interests.

Yet political science has much more to offer, even though its public image is primarily focused on the above mentioned aspect of application-oriented research. In the area of further analysis, universities also compete with the well-known foundations and think tanks whose newsletters are subscribed to by many of my former colleagues. Most of them are ideologically classifiable but have a good standing in the Brussels bubble. They are more active in self-marketing than university research. In my opinion, Departments of Political Science should invest a bit more in public relations, even if the financial resources are scarce.

After all, primarily party secretariats or the boards of directors of the political foundations decide to what extent political-science research is called for; but also personal assistants of politicians play a certain role. Since many of them were also students of political science, there is a certain proximity. Last but not least, also interns with a backgound in political science can help in building bridges between academia and politics.

Beyond professional consulting institutes, the contact between active politicians (and/or their staff) and the university is still expandable. Lobbyists in the European institutions have already started to invite staff from the offices of members of parliament or from the parliamentary groups to events and contact talks, since they have a certain influence on the political decisionmaking level. Employees in the parliaments often have a university background and are open to contacts. Invitations to seminars or events at the institutes can be helpful and enable a good exchange on concrete political problems. For practicioners of politics, a reflected view from outside is very fruitful and a stronger exchange between practice and theory would also promote the influence of political science on political decisions. 


\section{If I had one wish ...}

In recent years the field of social-science research has expanded to include a topic that currently dominates the media: Digitisation and automation and their effects on society and politics. In my opinion this topic should be analysed much more from a political-science perspective and/or the results should be made available to a broader public. Indeed, most of the recent literature, which is quoted in media on this subject has come from people with a background in the technical sciences. They are probably more aware of the explosive nature of the topic. Yet a closer engagement of political science with digitisation and automatization could reveal important aspects such as the similarities and differences between the political implications of technological revolutions in the past and current developments.

The following aspects merit research efforts by political scientists:

- In my opinion, interesting approaches can be found in elite research. The emergence of a very influential technical elite, which is mainly paid by the big monopolies such as Apple, Google or Facebook, leads to a dominance of applicationoriented research that ignores essential social elements. The dynamics that are currently giving such elites more and more influence need to be analysed from the point of view of their impact on society and politics. The fact that these elites are also extremely male-dominated is another factor that feminist scientists have already contributed to.

- The influences of technical development on the future of the work - and thus also on social partnership - are also much discussed, since the very rapid increase in precarious working conditions and a constantly decreasing degree of organisation, especially in the new high-tech areas, will undoubtedly call the old equilibria into question.

- Developments in the information society and in media behaviour are also likely to have a strong impact on democratic systems. Of course there are plenty of articles on the subject, but a comprehensive and competent political-science analysis is, to my knowledge, not accessible for a broader public.

- Social psychology has already been intensively concerned with the effects of new surveillance systems and the voluntary transfer of data on individuals. How surveillance, profiling, and data protection work in organizations or parties should be examined more closely.
- Before long, self-learning systems will become more present in social science research. Big data has been a topic in statistics for quite some time and exerts a certain fascination. It will be interesting to see how the importance of quantitative and quantitative methods will develop.

This is not just about a fashionable trend - there is hardly any other topic that dominates the media at the moment - but about the relatively small proportion of research relevant to political science in this area, which is outnumbered by the general hype of the media and countless publications. To leave this discussion to people coming from the sector would not be adequate, politicalscience and interdisciplinary research are necessary in this area in particular. The "Robot Council" recently setup in the Ministry of Transport and Innovation would be an interesting body for in-depth analysis. As far as I know, however, it currently has no political scientists on board.

I am, of course, aware that the proposals mentioned have very much to do with my own priorities of recent years, but I believe that a clearer and more visible positioning of political science on this topic could stimulate necessary and fruitful discussions.

In addition, I hope that political-science expertise will regain a greater significance in everyday politics. Not least because there has undoubtedly been an increase in the tendency towards emotion-driven decisions - and people - and more rationality in politics would be very useful. However, whether the hope that a more knowledge-based approach would be an effective counterweight is also worth closer analysis.

\section{Author}

Dr. Eva Lichtenberger - Psychology and Political Science at the University of Innsbruck, former member of the Tyrolean Landtag and of the Government of Tyrol, the Austrian Parliament and the European Parliament. At present lecturer in teachers' training, member of a working group on Artificial Intelligence of the Centre for European Policy Studies (CEPS), EUREGIO-Atelier, European Federalists. 